\title{
Radar observations of the diurnal tide in the tropical mesosphere-lower thermosphere region: Longitudinal variabilities
}

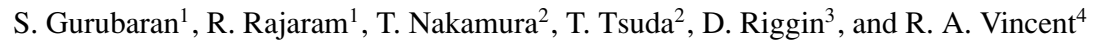 \\ ${ }^{1}$ Equatorial Geophysical Research Laboratory, Indian Institute of Geomagnetism, Tirunelveli, India \\ ${ }^{2}$ Research Institute for Sustainable Humanosphere, Kyoto University, Kyoto, Japan \\ ${ }^{3}$ Colorado Research Associates, Boulder, U.S.A. \\ ${ }^{4}$ Department of Physics and Mathematical Physics, University of Adelaide, Australia
}

(Received October 15, 2007; Revised July 5, 2008; Accepted July 5, 2008; Online published May 14, 2009)

\begin{abstract}
Significant attention is being paid in recent times by several observational and modeling studies to quantify the spatial and temporal variabilities of diurnal tide in the mesosphere and lower thermosphere (MLT) region. These variabilities are ascribed to spatial and temporal variations in the tidal forcing or interactions between the propagating tides and background wind, planetary waves or gravity waves. The present work makes use of simultaneous ground-based radar wind observations of different durations from five equatorial/low latitude sites in the Indian, Indonesian and Pacific sectors: Tirunelveli $\left(8.7^{\circ} \mathrm{N}, 77.8^{\circ} \mathrm{E}\right)$, Jakarta $\left(6.4^{\circ} \mathrm{S}, 106.7^{\circ} \mathrm{E}\right)$, Pontianak $\left(0.03^{\circ} \mathrm{N}\right.$, $\left.109^{\circ} \mathrm{E}\right)$, Kauai $\left(22^{\circ} \mathrm{N}, 160^{\circ} \mathrm{W}\right)$ and Christmas Island $\left(2^{\circ} \mathrm{N}, 157^{\circ} \mathrm{W}\right)$. This study delineates the longitudinal differences in the tidal characteristics in (i) interannual time scales over Tirunelveli and Kauai during 1993-2002, (ii) seasonal time scales over Christmas Island, Jakarta and Tirunelveli for the years 1993-1997 and (iii) shorter than seasonal time scales over Christmas Island, Pontianak and Tirunelveli during 1996-1997. An important observational feature noticed in this work is the differing behavior of the long-term tidal fields over Tirunelveli and Kauai. The monthly tidal amplitudes over Tirunelveli reveal a strong QBO signature whereas a similar, strong QBO signal could not be traced in the long-term observations from Kauai.
\end{abstract}

Key words: Mesosphere-lower thermosphere, middle atmospheric dynamics, atmospheric tides, MLT-QBO, mean winds and tides, tropical atmosphere.

\section{Introduction}

The upward propagating diurnal tide is an important dynamical feature of the middle atmosphere having significant impact on the energetics and dynamics at altitudes up to $\sim 100 \mathrm{~km}$, especially in the tropical region. Since the development of the classical tidal theory by Chapman and Lindzen (1970), the sun-synchronous migrating tidal modes have been studied extensively in the past (Forbes, 1984, for an earlier extensive review on this subject). Recent modeling and observational studies have focused on the processes responsible for the generation of non-migrating tides, whose presence in the middle atmosphere has been demonstrated by satellite observations made during the last decade (Talaat and Lieberman, 1999; Forbes et al., 2003; Oberheide et al., 2006). Significant attention has been paid in the recent past to the pronounced spatial and temporal variabilities in the diurnal tide revealed by ground-based and satellite-borne investigations pursued over the tropical region (Burrage et al., 1995; Chang and Avery, 1997; Khattatov et al., 1997; Vincent et al., 1998; Tsuda et al., 1999; Gurubaran and Rajaram, 1999; Talaat and Lieberman, 1999; Oberheide and Gusev, 2002; Forbes et al., 2003; Lieberman et al., 2004; Gurubaran et al., 2005; Oberheide

Copyright (c) The Society of Geomagnetism and Earth, Planetary and Space Sciences (SGEPSS); The Seismological Society of Japan; The Volcanological Society of Japan; The Geodetic Society of Japan; The Japanese Society for Planetary Sciences; TERRAPUB. et al., 2006; Lieberman et al., 2007). Apart from the role of non-migrating tides in causing such variabilities at mesospheric altitudes, contributions arising from variations in radiative and latent heat forcing (Hagan and Forbes, 2002; Lieberman et al., 2003, 2007), variations in eddy viscosity (Geller et al., 1997; Akmaev, 2001), latitudinal shear in zonal mean zonal wind and its seasonal variations (McLandress, 2002a, b) and interaction with planetary waves (Hagan and Roble, 2001; Mayr et al., 2003; Lieberman et al., 2004) and gravity waves (Mayr et al., 1998, 2001; Mayr and Mengel, 2005) have also been examined in recent model studies.

Radar-based investigations from the tropical sites, Christmas Island, Jakarta, Pontianak and Tirunelveli, have contributed to delineating the temporal variabilities of the diurnal tide close to the equator (Chang and Avery, 1997; Vincent et al., 1998; Tsuda et al., 1999; Gurubaran and Rajaram, 1999). A recent effort combined the long-term radar data sets for the years 1993-1999 from Jakarta and Tirunelveli along with the satellite derived Outgoing Longwave Radiation (OLR) and examined the interannual variability of the diurnal tide that was observed over both sites (Gurubaran et al., 2005). The diurnal tide amplitudes over Jakarta, when examined on monthly basis, were seen to be responding to the intensity of deep tropical convection in the western Pacific. It was suggested then that the lower atmospheric large-scale convective systems originating over the western Pacific region in response to the El Nino South- 
ern Oscillation (ENSO) facilitated excitation of nonmigrating tides through latent heat release or large-scale redistribution of water vapor that were to compete with the dominant migrating tide and thereby possibly induce the observed interannual variability in the diurnal tide. Miyoshi (2006) used a general circulation model to examine the eastward propagating diurnal tide of zonal wavenumber 3 (DE3) and its relation to the convective activity in the tropical troposphere. Not only the day-to-day variation in the DE3 nonmigrating tide seems to be closely related to the temporal variation of the rainfall rate in the tropics, but the model results of Miyoshi (2006) show that the zonal mean zonal wind in the equatorial MLT region is influenced by the moist convective activity. Using a primitive equation model, Lieberman et al. (2007) emphasize that water vapor heating is the major contributor to the tidal amplitude enhancement observed over Kauai during 1997-1998. Their calculations for the water vapor heating reveal a stronger forcing of the migrating diurnal tide due to the altered heating patterns during the ENSO event.

Reports have emerged in the past that relate the observed interannual variabilities in the diurnal tide to the background wind in the intermediate altitudes, which is largely influenced by the quasi-biennial oscillation (QBO) in the equatorial region (Burrage et al., 1995; Vincent et al., 1998; Tsuda et al., 1999; Gurubaran and Rajaram, 1999). In particular, multi-year observations over Adelaide $\left(35^{\circ} \mathrm{S}\right.$, $\left.138^{\circ} \mathrm{E}\right)$ revealed diurnal tide amplitudes being larger than the cimatological average during years when the QBO was in the eastward phase and smaller than average when the QBO was in its westward phase (Vincent et al., 1998). Though Hagan et al. (1999) could not explain the observed interannual tidal variations in terms of the effects of the QBO when they performed numerical experiments with the global scale wave model (GSWM), later model studies by McLandress (2002c) and Mayr and Mengel (2005) could simulate the interannual variations that were attributed to the latitudinal shears of the mean winds and their interannual variations and momentum deposition by gravity waves undergoing QBO modulation at lower levels, respectively. Mayr and Mengel (2005) have stressed the complexities that arise due to nonlinear interactions between the gravity waves, tides and mean winds resulting in the variable nature of the interannual modulation of the diurnal tide in the upper mesosphere.

Amidst the uncertainties that still prevail in understanding the probable mechanisms that drive the interannual variations in the diurnal tide, long-term radar observations continue to provide valuable information on the tidal variabilities in various time scales. The observational efforts also support those modeling efforts that examine how these variabilities could be related to the heat and momentum sources of the kind reported in the literature. One of the objectives of the analysis presented in this work is to extend the earlier study by Gurubaran and Rajaram (1999) and Gurubaran et al. (2005) to observations from Tirunelveli stretching beyond 1999. Though a signature of the ENSO during 19971998 appears to be present in the MLT tidal field, the tidal analysis performed for the wind data from Tirunelveli during the subsequent years (1999-2006) has clearly shown the presence of a QBO modulation of the tidal amplitudes. Low tidal activity observed throughout 2000 occurred during the extended easterly QBO phase that began in early 1999 and ended in early 2001. Such an analysis was also performed for the long-term data sets from Kauai for the years 19932002. It will be shown in the present work that the QBO signature is relatively weaker over Kauai during most of the observation duration and a stronger seasonal variation in the tidal amplitudes is a regular feature that repeats every year. This comparative exercise performed for the two sites separated in longitude by more than $120^{\circ}$ brings out the differences in the long-term behavior of the diurnal tide and its dependence on QBO over these two regions.

The seasonal variation in the diurnal tide has been attributed by various modelers to (i) variation in eddy diffusion induced by breaking gravity waves (Geller et al., 1997; Meyer, 1999; Akmaev, 2001), (ii) gravity wave-tide interactions resulting in momentum deposition (Mayr et al., 1998, 2001; Meyer, 1999; Mayr and Mengel, 2005), (iii) meridional advection and its seasonal variations (McLandress, 2002b) and (iv) planetary wave-tide interaction resulting in the generation of nonmigrating tides and other secondary waves (Hagan and Roble, 2001; Mayr et al., 2003; Lieberman et al., 2004). We have not yet reached a stage wherein a specific mechanism can explain the seasonal variations reported in the ground-based radar and satellite diurnal tide observations.

Enabled by the availability of simultaneous data on mesospheric winds from the three low latitude sites, Christmas Island, Jakarta and Tirunelveli, for the years 19931997, we undertake comparisons of monthly variations of diurnal tidal amplitudes and phases over these sites and assess the longitudinal differences in the average tidal characteristics on month-to-month basis. Such an exercise has not been carried out earlier for the low latitude region with any long-term data sets of the kind utilized in the present work. Any outcome of this exercise will have relevance to the ongoing modeling efforts that aim to simulate the observed seasonal variations in the diurnal tide.

Though efforts are still being made to understand the tidal variabilities in the interannual and seasonal time scales from the modeling perspective, the radar observations reveal richness in the tidal variations in shorter than seasonal time scales that are yet to be addressed in detail by any of the numerical models. With similar hourly data sets available from the three MF radar sites, Tirunelveli, Pontianak and Christmas Island, during the years 1996 and 1997, we closely examine the tidal variations and their longitudinal differences over short time scales (10-30 days). We address the role of deep tropical convection in causing the observed variabilities in the diurnal tide over each of the sites. For this purpose, the daily OLR data sets for the tropical region (within $\pm 10^{\circ}$ latitude) are utilized for selected time intervals of about five months and a correlative study is performed to assess whether the spatial and temporal distribution of the deep convective clouds could explain the observed temporal variations of the diurnal tide at MLT heights.

The observational results from this work are presented in three parts. The interannual variabilities of the diurnal 
tide derived from the long-term MF radar observations from Kauai and Tirunelveli over the years 1993-2002 and their dependence on stratospheric QBO are examined in Section 3.1. Section 3.2 deals with the seasonal variations of diurnal tide characteristics over the low latitude sties, Christmas Island, Jakarta and Tirunelveli and their longitudinal differences from simultaneous data sets available for the years 1993-1997. Finally, the short-term (less than seasonal time scales) variabilities over the three MF radar sites, Christmas Island, Pontianak and Tirunelveli, are examined in Section 3.3 and an attempt is made to establish the role of deep tropical convection in the western/central Pacific region in causing these variabilities by pursuing a correlative analysis.

\section{Observations}

The MF radars at Christmas Island, Kauai, Tirunelveli and Pontianak, all operating at $1.98 \mathrm{MHz}$, used the spaced antenna technique to determine horizontal winds in the MLT region (Vincent and Lesicar, 1991), whereas the meteor wind radar (MWR) at Jakarta utilized echoes arising from meteor trails (Tsuda et al., 1995). The MF radar wind data were sampled at 2-min and 2-km intervals and were used to construct hourly averaged time series of zonal and meridional winds. The MF radars adopted data rejection criteria that eliminated outliers or those velocity estimates that were greater than certain prescribed values. In two of the present studies that are aimed to derive the diurnal tide climatologies in the interannual and seasonal time scales, harmonic fits over sliding 30-day hourly data segments were then performed to determine the amplitudes and phases of the diurnal tide in the least squares sense (Vincent et al., 1998). At Jakarta, the meteor echoes were binned onto 31-day segments and the wind estimates in the 31-day segment were then averaged according to their local time and fitted with the 24-hour component to yield the amplitude and phase of the diurnal tide (Tsuda et al., 1999). The short-term tidal study taken up in this work focuses on tidal variabilities in shorter than seasonal time scales. Simultaneous MF radar observations from Christmas Island, Pontianak and Tirunelveli, for the period 1996-1997 are available for this study, for which the tidal amplitudes and phases were computed from harmonic fits applied to 10-day segments. While examining the tidal parameters, we restrict the altitude region to $84-94 \mathrm{~km}$ because of the better data acceptance rates at these heights. In the plots shown in this paper the error bars have been omitted for clarity. Typically, the uncertainty in the amplitude that results from the deviations in the fit to the observed data is in the range $1-3 \mathrm{~m} \mathrm{~s}^{-1}$ and the corresponding error in phase is in the range $0.5-2 \mathrm{~h}$.

\section{Results}

\subsection{Interannual variability and the QBO}

Figure 1 (middle and bottom panels) shows the monthly amplitudes of the diurnal tide in mean zonal wind at $86 \mathrm{~km}$ over Kauai and Tirunelveli during the years 1993-2002. Results for the mean meridional wind are shown in Fig. 2. The symbols joined by thin curves represent the observed amplitudes and the thick curves are obtained by five-point running means. The beginning of every year is indicated by
Zonal wind at $10 \mathrm{mb}$ and diurnal tide at $86 \mathrm{~km}$
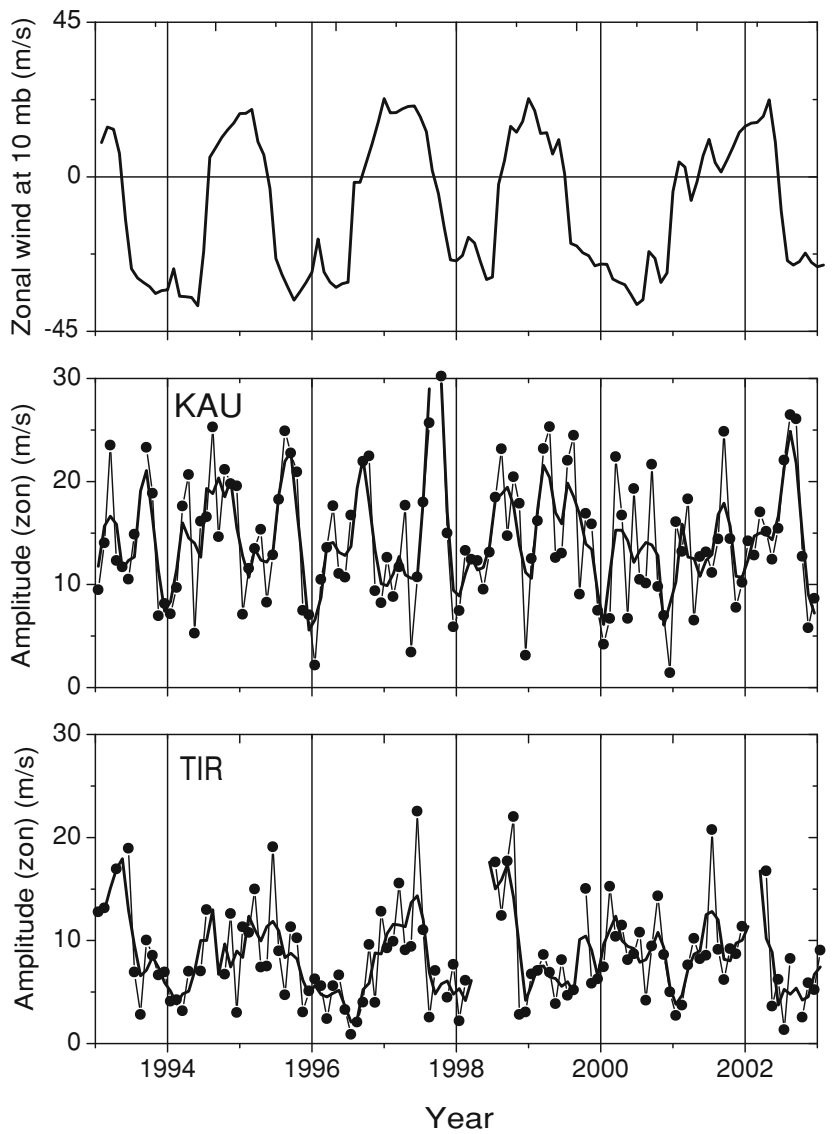

Fig. 1. Monthly (filled circles) derived amplitudes of the diurnal tide in zonal wind at $86 \mathrm{~km}$ over Kauai (KAU) (middle) and Tirunelveli (TIR) (bottom). The thick continuous curves represent five-month running means. The mean zonal wind at $10 \mathrm{mb}(\mathrm{hPa})$ observed at Singapore is shown in the top panel.

the label shown on the horizontal axis. In the top panels of Figs. 1 and 2 is shown the mean zonal wind at $10 \mathrm{hPa}$ over Singapore derived from radiosonde launches. The QBO winds are global and the stratospheric mean zonal wind observed over an equatorial station can be considered to represent the phase of the QBO (Andrews et al., 1987). It has also been known that the period of the QBO varies between 22 and 34 months (Baldwin et al., 2001) and that can be verified with the $10 \mathrm{hPa}$ winds shown in Figs. 1 and 2 .

A large interannual variability of the upper mesospheric diurnal tide can be noticed for Tirunelveli. With regard to the zonal component at $86 \mathrm{~km}$ over Tirunelveli, large diurnal tide (with amplitudes in the range 10-20 m/s on the average) activity occurred during 1993, 1995 and 1997 when the QBO phase was eastward (or westerly). Weaker tidal activity is noticed during early 1994 and throughout 1996. Beginning with the year 1997, the diurnal tide amplitude for the meridional component showed remarkable correlation with the phase of the QBO. An extended QBO westward phase occurred during 1999-2001. Smaller tidal amplitudes $(2-10 \mathrm{~m} / \mathrm{s}$ on average) were observed during this period. The zonal component did not seem to respond to the QBO westward phase during 2000. Earlier, Gurubaran and 
Zonal wind at $10 \mathrm{mb}$ and diurnal tide at $86 \mathrm{~km}$
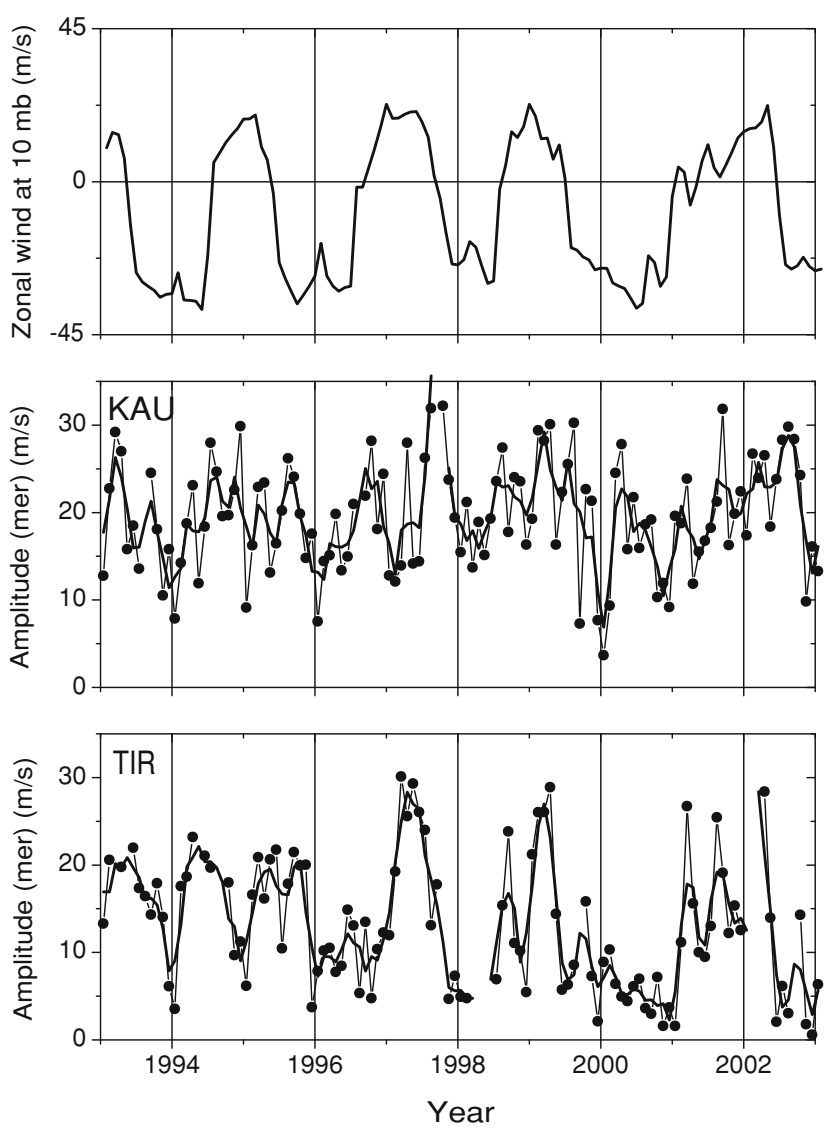

Fig. 2. Same as Fig. 1 but for meridional wind component at $86 \mathrm{~km}$.

Rajaram (1999) used the same data sets from Tirunelveli but for the years 1993-1997 and reported the interannual variability of the diurnal tide over Tirunelveli with the suggestion that it might be associated with the stratospheric QBO.

In contrast to the diurnal tide variation over Tirunelveli, the tidal activity over Kauai shows a relatively weaker interannual variability. A semi-annual variation was observed to be a prominent feature over Kauai, with equinoctial maxima and solstitial minima that repeated almost every year. During September 1997, large tidal amplitudes (40-50 m/s) were observed in both zonal and meridional components over Kauai. This coincided with the occurrence of the El Nino phenomenon across the Pacific region. Earlier, Lieberman et al. (2007) reported this feature observed over Kauai and associated it with the enhanced radiative heating and strengthening of the migrating tidal component due to the redistribution of large-scale tropical moisture during the ENSO event. It is to be noted that the low latitude sites, Tirunelveli and Jakarta, showed enhanced tidal activity (with amplitudes of 25-30 m/s) during early 1997 prior to the onset of the El Nino (Gurubaran et al., 2005). It is not known at this moment whether the eastward phase of the stratospheric QBO around this time provided favorable conditions for the enhanced tidal activity observed at MLT heights over Tirunelveli and Jakarta.

\subsection{Longitudinal variability in seasonal time scales}

We now proceed to examine the longitudinal variability of the diurnal tide at the three low latitude sites, Christmas
Diurnal tide at $86 \mathrm{~km}$
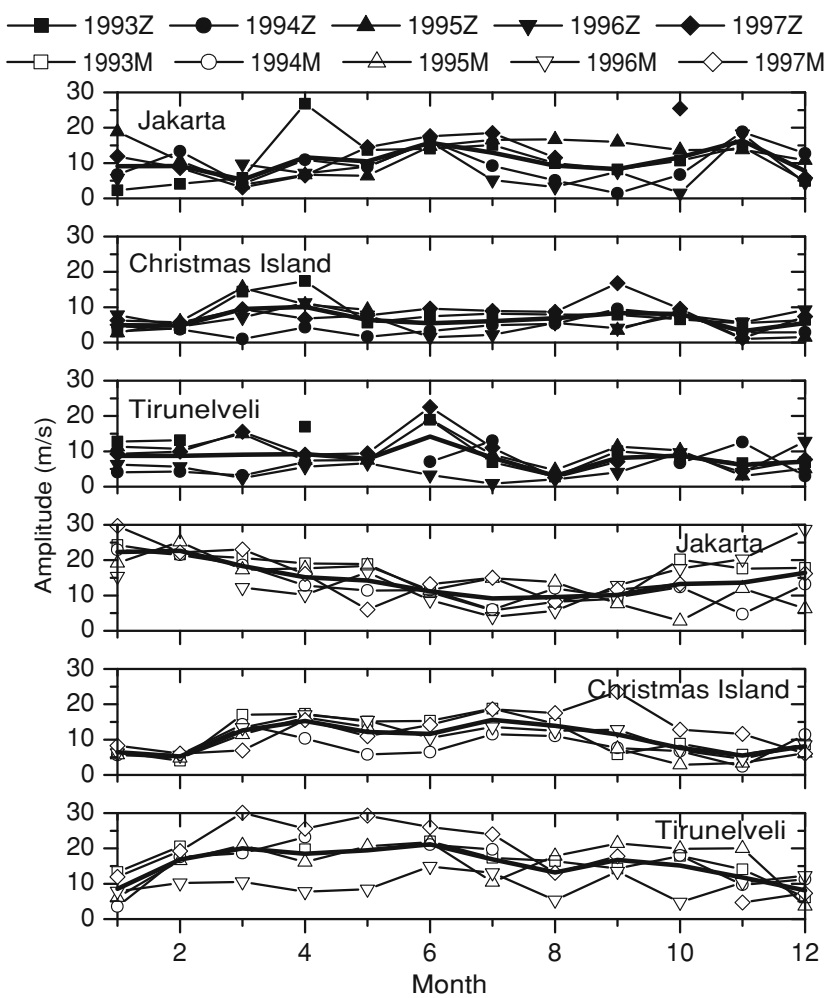

Fig. 3. Monthly amplitudes of the diurnal tide in zonal (filled symbols) and meridional (unfilled symbols) at $86 \mathrm{~km}$ over Jakarta $\left(6.4^{\circ} \mathrm{S}, 106.7^{\circ} \mathrm{E}\right)$, Christmas Island $\left(2^{\circ} \mathrm{N}, 157^{\circ} \mathrm{W}\right)$ and Tirunelveli $\left(8.7^{\circ} \mathrm{N}, 77.8^{\circ} \mathrm{E}\right)$ for the years 1993-1997. The top three panels depict results for zonal wind component and the bottom three panels are for the meridional wind component. See text for further details.

Island, Jakarta and Tirunelveli during the period 1993-1997 for which simultaneous observations are available. Monthly amplitudes are first compared to determine the seasonal variations in tidal activity over these sites. We later examine the phase of the diurnal tide over each of these sites and the phase difference between each station pair in order to retrieve useful information on average tidal characteristics over these regions. Earlier, Tsuda et al. (1999) investigated the tidal characteristics over Christmas Island, Jakarta and Pontianak with limited data sets (1995-1997) and compared the results with the Global Scale Wave Model outputs (Hagan et al., 1995). For the first time, they reported significant longitudinal differences in the tidal characteristics over Christmas Island and the Indonesian stations suggesting the presence of nonmigrating tides. Gurubaran et al. (2005) examined the long-term (1993-1999) variability of the diurnal tide amplitude in the meridional wind over Jakarta and Tirunelveli and as mentioned earlier, focused primarily on delineating the interannual variability. In a separate study, Gurubaran and Rajaram (1999) also investigated the seasonal variability of the tidal amplitudes and phases over Tirunelveli with data sets for the years 1993-1997. Their study showed that the diurnal tide in the meridional wind over Tirunelveli was characterized by minima in the winter seasons and intermittent maxima during rest of the seasons. Larger amplitudes $(20-25 \mathrm{~m} / \mathrm{s})$ in zonal component appeared in June every alternate year. Each of these studies 
had limitations in that they used limited data sets or examined only the meridional component. In the work presented here, we combine the earlier results making use of the same data sets used in the previous studies and highlight the longitudinal differences in the seasonal pattern of individual tidal parameters over the three regions.

We begin by showing the amplitude of the diurnal tide at $86 \mathrm{~km}$ over the three sites in Fig. 3. Filled symbols in the top three panels are for the zonal component and unfilled symbols in the rest of the panels are for the meridional component. The thick curve shown in each of the panels represents the mean amplitude variation and aids in visually inspecting the average seasonal dependence over each of the sites. The zonal component over Jakarta shows little seasonal variation with a tendency for achieving larger amplitudes (in the range 15-20 m/s) during June and July and smaller amplitudes during January and February in certain years. On the other hand, the meridional component reveals a pronounced annual variation during all the years as reported earlier (Tsuda et al., 1999; Gurubaran et al., 2005). On average, small tidal amplitudes $(5-15 \mathrm{~m} / \mathrm{s})$ are present during local winter months (June-August), whereas summer months (December-February) are marked by pronounced tidal activity (with amplitudes in the range 20$30 \mathrm{~m} / \mathrm{s}$ ). In this context we note that the maritime continent is characterized by a seasonal cycle in the deep convective activity. Deep convective regions south of the equator intensify during the southern summer, while during the local winter months the region remains 'dry'. A strong seasonal variation in the diurnal tide in meridional component over Jakarta is probably linked to the seasonal cycle of the deep tropical convective activity occurring over the maritime continent. The responses in the meridional and zonal tidal wind fields are distinctly different and the reasons for these differing behaviors are yet to be understood.

Results for Christmas Island depicted in Fig. 3 reveal larger amplitudes $(10-20 \mathrm{~m} / \mathrm{s})$ during the northern spring equinox months and smaller amplitudes $(5-10 \mathrm{~m} / \mathrm{s})$ during the northern winter months. There was considerable yearto-year variability in the zonal component, especially during the equinox and summer months. However, the mean amplitude was in the range of $5-10 \mathrm{~m} / \mathrm{s}$ for the zonal component and $10-15 \mathrm{~m} / \mathrm{s}$ for the meridional component during most of the years. During the northern summer months (June-August) of 1993, 1996 and 1997, the observations at Christmas Island yielded enhanced tidal amplitudes (10$20 \mathrm{~m} / \mathrm{s}$ ). During 1994, the amplitudes were considerably smaller in both zonal and meridional components till the month of June. In general the amplitudes for the meridional component were larger than those for the zonal component.

With regard to the tidal amplitudes for Tirunelveli for the years 1993-1997, the seasonal variation shows considerable interannual variability in both the zonal and wind components with the tendency for larger amplitudes during the equinox months and smaller amplitudes during winter months. The seasonal variation for the zonal component reveals an additional maximum in June during 1993 and 1995. The 1997 meridional amplitudes were considerably larger than during other years. As is the case for Christmas Island, the tidal amplitudes in the zonal component over Tirunelveli
Diurnal tide at $86 \mathrm{~km}$

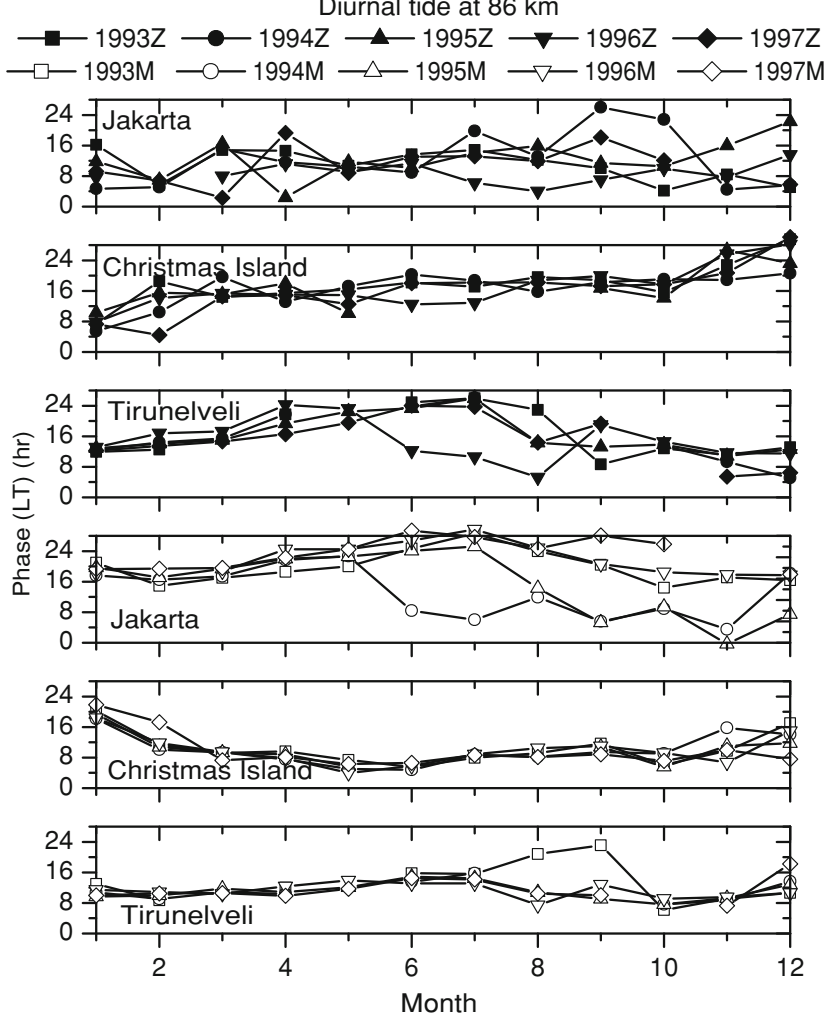

Fig. 4. Same as Fig. 3 but for the phase of the diurnal tide.

were considerably smaller ( $\sim 5 \mathrm{~m} / \mathrm{s}$ ) during 1994 and 1996, the years when the stratospheric QBO was in the westward phase (refer to Fig. 1). These features were earlier reported in the work by Gurubaran and Rajaram (1999).

The phases (in local time (LT)) of the diurnal tide at 86 $\mathrm{km}$ over the three sites are depicted in Fig. 4 and the difference in phases between each station pair are plotted in Figs. 5 and 6 separately for the zonal and meridional components. For the symmetric diurnal tidal mode $(1,1)$, the classical tidal theory predicts similar phases for the zonal component and out-of-phase behavior for the meridional components for stations on either side of the equator. Hemispheric differences in tidal forcing would lead to the excitation of asymmetric tides. Additional tidal modes generated due to a variety of processes may shift the phases expected from symmetric tides accompanied by significant modulation of amplitudes.

The phases depicted in Fig. 4 for the three sites show remarkable seasonal patterns and are in agreement with the earlier reports by Tsuda et al. (1999) and Gurubaran and Rajaram (1999). Tirunelveli and Jakarta, being the mirror sites located within $6-9^{\circ}$ latitude on either side of the equator, reveal the out-of-phase behavior for the meridional component during certain periods (April 1994, April-May 1995, May 1996 and April-May 1997) as can be noted in Fig. 6. On several occasions, the phase differences were between 6 and 9 hours. During the northern winter months of December-February, the phase difference for the JakartaTirunelveli pair was in the range 6-9 hours, whereas the Jakarta-Christmas Island pair reveals phase differences in the range $0-6$ hours. The Christmas Island-Tirunelveli pair 
Diurnal tide phase differences in zonal wind at $86 \mathrm{~km}$
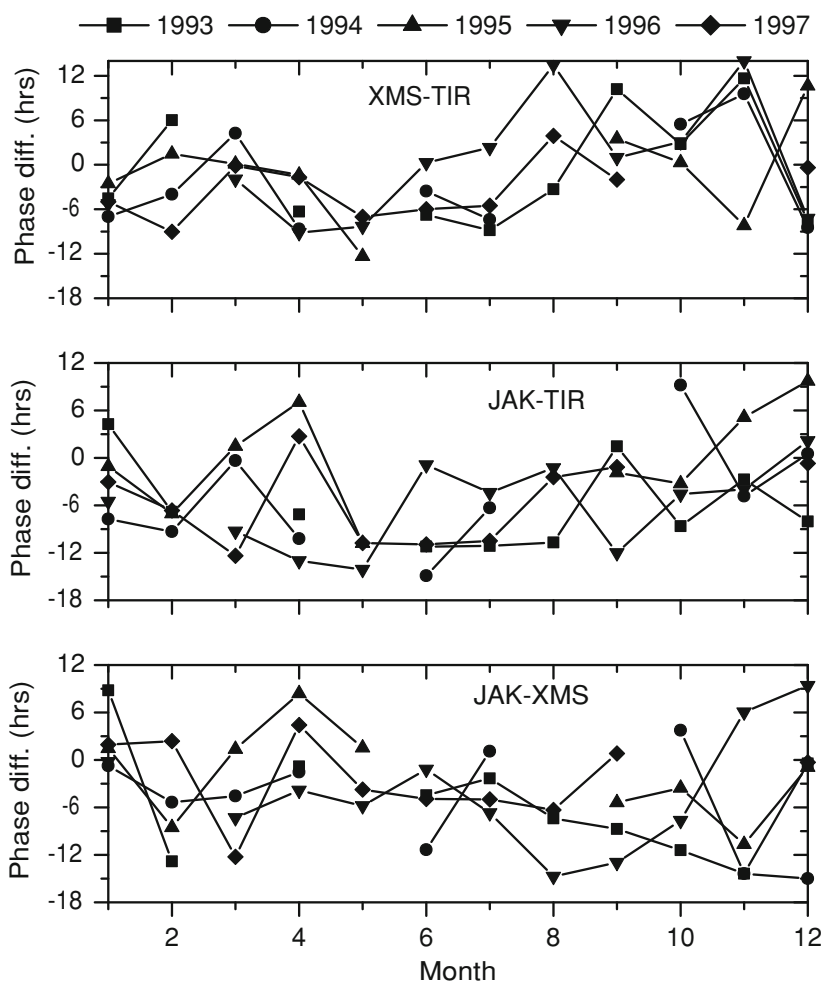

Fig. 5. Phase differences between individual station pairs for the zonal component at $86 \mathrm{~km}$.

shows a striking annual progression. The phase difference was in the range 6-9 hours during the summer and winter months, while it was in the range 0-3 hours during both the equinoctial periods (March-April and SeptemberOctober). Referring to Fig. 4, it can be seen that during the first half of every year, the phase of the meridional component advanced to earlier hours at Christmas Island and during the second half of the year it receded to later hours. An opposite behavior is seen for Tirunelveli with the phases differing by 6-9 hours during June.

The zonal component for Christmas Island at $86 \mathrm{~km}$ had phases mostly in the range 12-18 LT except during November-February when the times of amplitude maxima shifted to values outside this period. The zonal phases for Tirunelveli were receding to later hours during the first part of the year and advancing to earlier hours during the second half. The zonal phases for Jakarta exhibited considerable month-to-month variability, especially, during the local summer months of November-February. Looking at the phase differences for the zonal component shown in Fig. 5, no clear trend can be seen for any of the station pairs.

In an effort to address the observed tidal phases and their differences in the context of recent tidal model predictions, we now examine the results from a recent version of the Global Scale Wave Model (GSWM-02) corresponding to a combination of migrating and nonmigrating tidal solutions for the geographic locations close to the three radar sites. The GSWM is a state-of-the art two-dimensional, steady state, numerical tidal model developed by Hagan et al. (1995), whose results in the form of monthly tidal pertur-
Diurnal tide phase differences in meridional wind at $86 \mathrm{~km}$
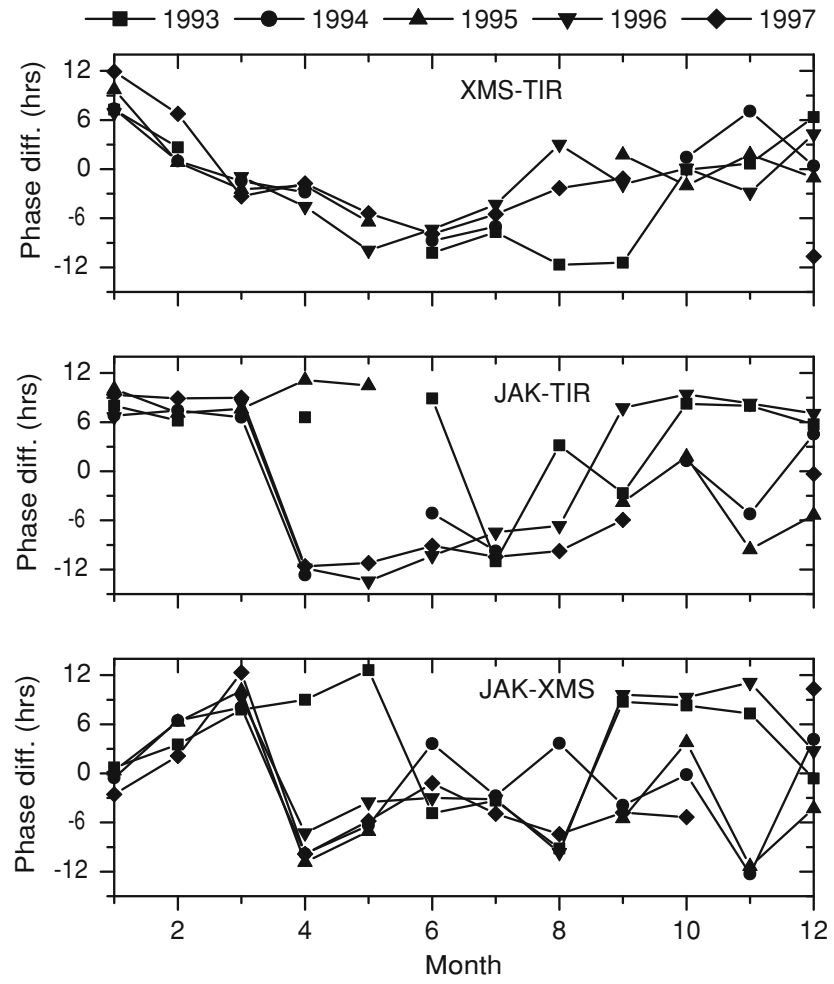

Fig. 6. Same as Fig. 4 but for meridional component.

bations in temperatures and winds from ground to $125 \mathrm{~km}$ are readily available to the scientific community through the worldwide web. With linearized, steady-state assumptions, the GSWM-02 solves for the tidal perturbations combining the migrating and nonmigrating components with zonal wavenumbers up to 6 . The forcings included in the model are: (i) the radiative heating produced by the absorption of solar UV and EUV radiation in the stratosphere, mesosphere and thermosphere and IR radiation in the troposphere, and (ii) the latent heating associated with the deep convective activity in the troposphere (Hagan and Forbes, 2002).

In Fig. 7 we show the GSWM02 results for the phases of the diurnal tide at $86 \mathrm{~km}$ corresponding to the three radar locations for every month during a calendar year. An out-ofphase relationship for the northern and southern locations reveals that the migrating tide is the dominant dynamical feature in the model. The phases during equinoxes are consistent over all the locations with zonal phases in the range 12-15 hrs (LT) and meridional phases in the range 6-8 hrs (LT) for the northern locations and 18-21 hrs for the southern location. Significant deviations from these values can be noticed for the solstice months of November-February and June. Significant longitudinal differences arise during these months as well, possibly contributed by the nonmigrating tidal modes in the model.

An examination of Figs. 4 and 7 provide enough indications to show that the model predictions for both zonal and meridional components substantially deviate from the observed phases, especially during solstice months. The model phases obtained for Christmas Island are closest to 
GSWM02 results for diurnal tide phases
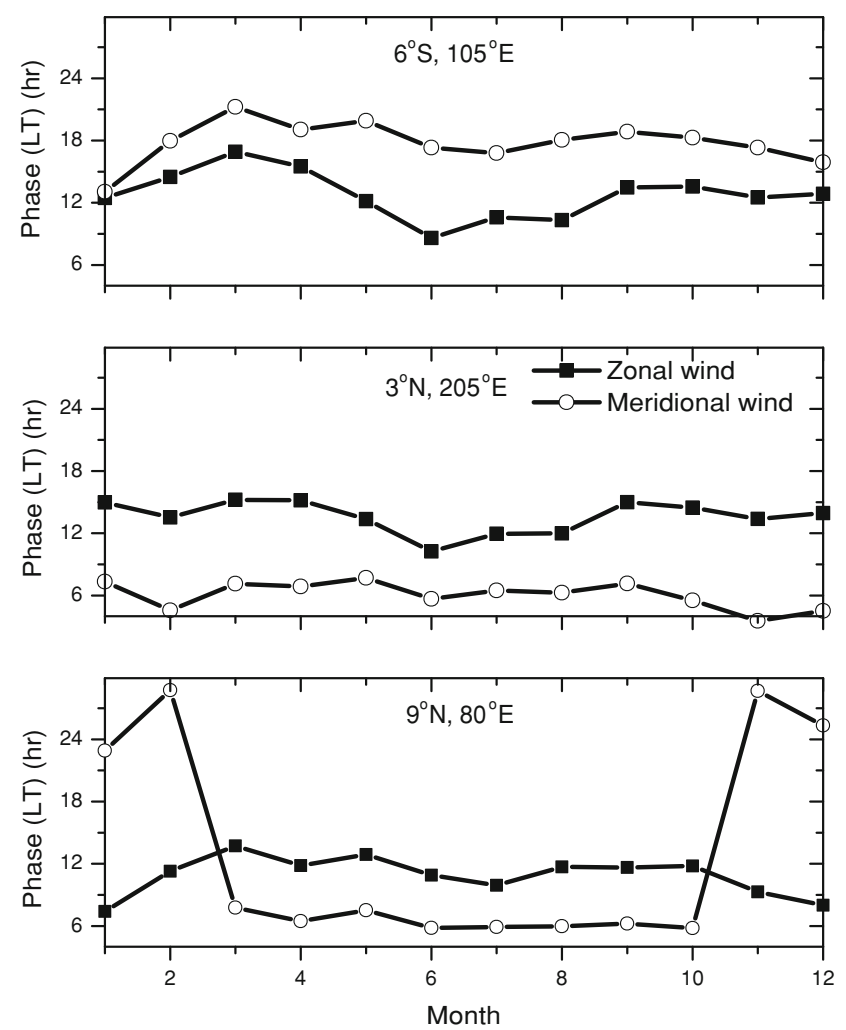

Fig. 7. GSWM02 outputs for diurnal tide phases for $86 \mathrm{~km}$ at geographic locations close to the three radar sites (Jakarta in the top panel, Christmas Island in the middle panel and Tirunelveli in the bottom panel).

the observed phases in both zonal and meridional components only during equinox months. Considerable year-toyear variability can be noticed for the tidal phases over Jakarta and this would pose difficulties for a comparison with the model phases. The observed seasonal swings in the zonal component over Tirunelveli are quite significant (up to a maximum of 12 hours between the two solstices) when compared to the model phases that show only 4-6 hours swing between the two solstices. A notable shortcoming in the model is the absence of the remarkable annual progression noticed in the phase difference for the Christmas Island-Tirunelveli pair, especially in the meridional component, for all the years depicted in Fig. 6 .

\subsection{Short-term tidal variabilities}

The emphasis in this section is on delineating short-term tidal variabilities during 1995-1997 when simultaneous observations from the three radar sites were available. Nakamura et al. (1997) earlier addressed short-term tidal variabilities with tropical and subtropical MLT radar observations from Jakarta, Adelaide, Kauai and Christmas Island. Though the seasonal variabilities were similar over the four sites, there were significant differences in the short-term variabilities in time scales of $\sim 5$ to 30 days with low coherences noticed in amplitude and phase variations between the sites. The study by Nakamura et al. (1997) revealed the role of gravity wave-tidal interactions in producing the complex tidal variabilities observed over the low latitude sites.

In this work we examine the short-term tidal variabilities with a different perspective. We initiated this part of the study with the conviction that some of the tidal variabilities observed at low latitudes could be ascribed to the source variations in the troposphere. As in the previous work of Gurubaran et al. (2005) that examined long-term tidal climatologies, herein we consider deep tropical convection as a potential source responsible for causing some of the observed short-term tidal variations at MLT heights. Low values of daily OLR are presumed to indicate presence of deep convective clouds with inherent diurnal precipitation rates responsible for the generation of nonmigrating tides. Any temporal and spatial variations of such clouds are expected to modify the strength of the tidal modes propagating upwards. Variations in tidal amplitudes observed at MLT heights may then correlate with the variations in the location and strength of deep convective clouds in the vicinity of the radar sites. The background mean winds at intermediate altitudes through which the tides propagate are likely to influence tidal characteristics in longer time scales (seasonal and beyond) but planetary waves and gravity waves may contribute to tidal variabilities in the shorter time scales (Walterscheid, 1981; Teitelbaum and Vial, 1991).

We analyze short-term tidal variabilities observed during two solstice seasons: (1) June-August 1996 when a summer monsoon was active over India and Indo-China region and (2) November 1996-January 1997 when similar conditions were prevalent over the maritime continent and in the western Pacific region. The stratospheric QBO was in the westward phase then, and Tirunelveli MF radar observations yielded smaller $(5-10 \mathrm{~m} / \mathrm{s})$ monthly tidal amplitudes during the northern summer months of 1996, whereas during the northern winter months of 1995-1996 moderate amplitudes $(10-20 \mathrm{~m} / \mathrm{s})$ were obtained. We had mentioned earlier that the tidal activity at mesospheric altitudes tends to be accompanied by diminished amplitudes during the QBO westward phase. The overall reduced amplitudes during mid-1996 were probably due to unfavorable background wind conditions under the influence of QBO westward phase.

For the present analysis, ten-day segments of data were used to compute the amplitudes and phases of the diurnal tide at the three low latitude stations, Tirunelveli, Christmas Island and Pontianak. Tidal parameters were derived for five heights between 86 and $94 \mathrm{~km}$ in order to check whether the variations were coherent over a wider altitude region.

The results for the 140-day data sets (day numbers 151290) obtained between June and October of 1996 are shown separately for the three sites in Figs. 8 and 9 (Tirunelveli in the top, Christmas Island in the middle and Pontianak in the bottom panels). A significant 30-40 day modulation of the diurnal tide is noticed for Tirunelveli in Fig. 8 with strongest amplitudes (15-25 m/s) occurring around day numbers 170 , 200, 240 and 275. A similar variability is noticed at other sites as well but the times of occurrence of high and low tidal activities were somewhat different. For example, the Christmas Island amplitudes appear to be shifted in time by about 10-20 days during the first half of this period. The 30-40 day variability over Pontianak was weaker then and there was a significant altitude variation in the tidal amplitudes between day numbers 165 and 185. Between day 
Diurnal tide in meridional wind over TIR, $\mathrm{CHI}$ and PON
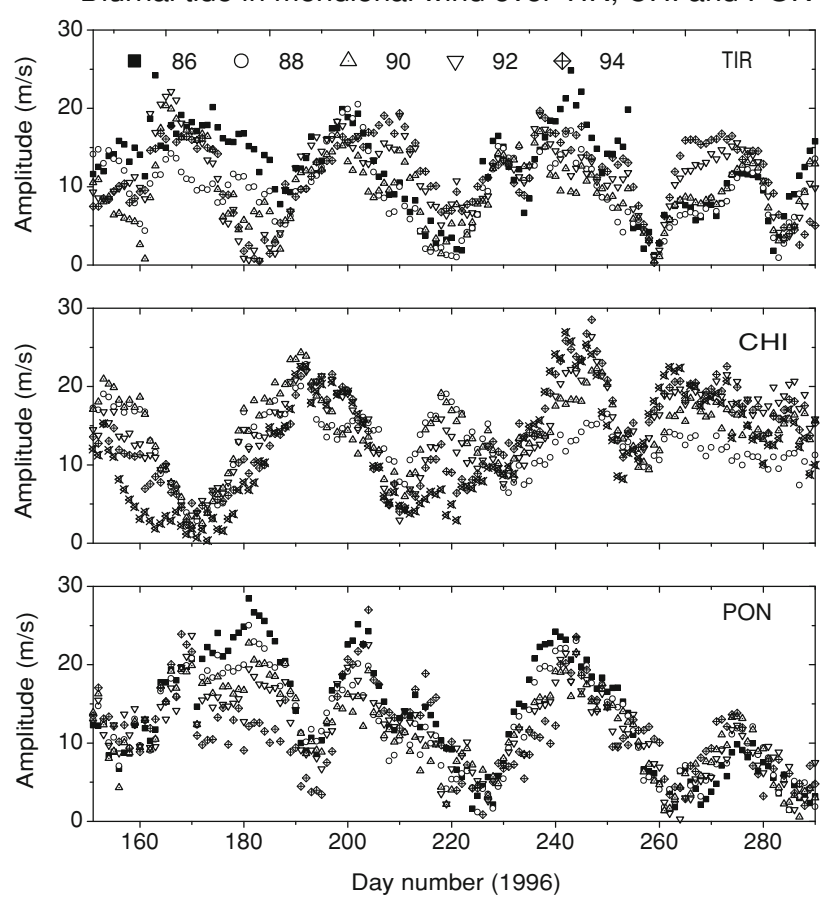

Fig. 8. Diurnal tide in meridional wind over the three stations, Tirunelveli (top), Christmas Island (middle) and Pontianak (bottom) derived from 10-day sliding segments for the period June-October 1996. Symbols shown are for the heights $86-94 \mathrm{~km}$ sampled at $2 \mathrm{~km}$ intervals.

numbers 190 and 290, the tidal variabilities over Tirunelveli and Pontianak are quite similar.

The phases plotted in Fig. 9 indicate the existence of distinct longitudinal differences during the chosen period. The phases over Tirunelveli advanced to earlier hours (from 6$12 \mathrm{hrs}$ to $0-4 \mathrm{hrs}$ in the 86-94 $\mathrm{km}$ height region) during the day numbers 151-230 while they receded to later hours during the rest of the period. This slow variation in the phases can be noticed in the monthly estimated phases shown in Fig. 4. The Christmas Island phases did not vary much between day numbers 190 and 290 with vertical wavelengths mostly in the range $30-45 \mathrm{~km}$. On the other hand, the phases over Pontianak revealed abrupt changes around day numbers 220 and 260 when the amplitudes reached minimum values. As occurs over Tirunelveli, the phases over Pontianak retarded to later hours between day numbers 230 and 280.

We now examine the daily OLR variations during the two solstice seasons chosen for this analysis. The daily OLR maps reveal that during the northern summer monsoon months, regions north of the equator were convectively active, whereas during the southern summer months, the maritime continent and western-to-central Pacific regions host convective clouds. In order to facilitate comparison with tidal amplitudes determined for the three radar sites, we consider three longitude sectors: (1) $80-120^{\circ} \mathrm{E}$, (2) $100-$ $140^{\circ} \mathrm{E}$ and (3) $150-180^{\circ} \mathrm{E}$. We anticipate a stronger tidal response to the deep convective activity over the $80-120^{\circ} \mathrm{E}$ sector for the Indian site, $100-140^{\circ} \mathrm{E}$ sector for the Indonesian site and $150-180^{\circ} \mathrm{E}$ for Christmas Island.

Results from this correlative analysis are shown in
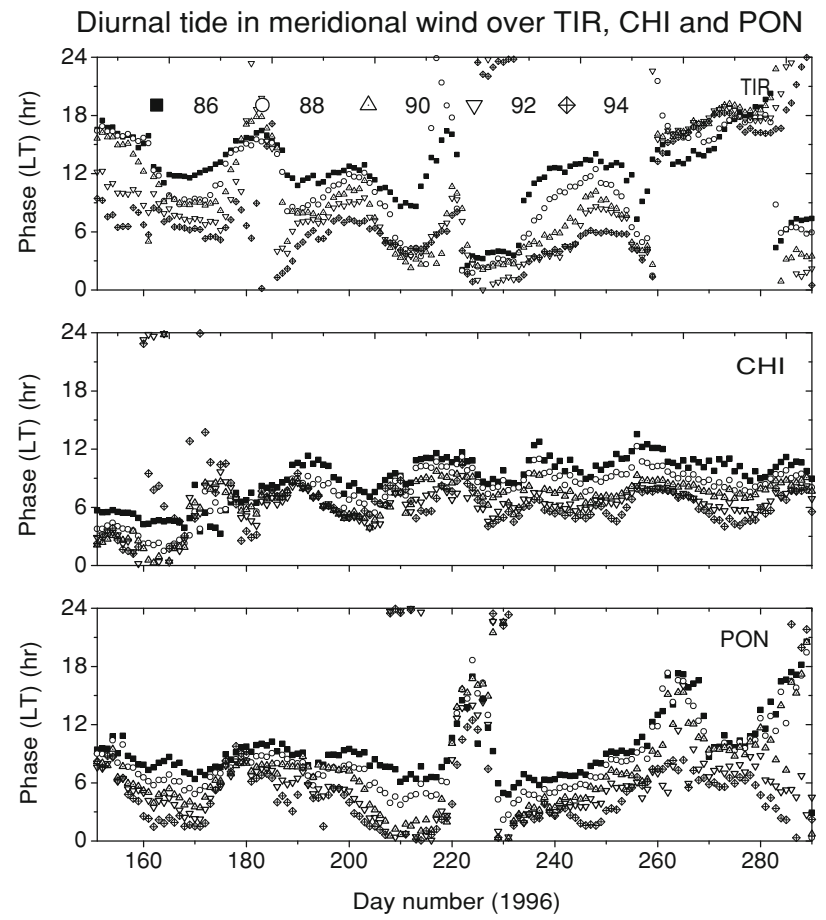

Fig. 9. Same as Fig. 8 but for the phase of the meridional component estimated for the period June-October 1996.

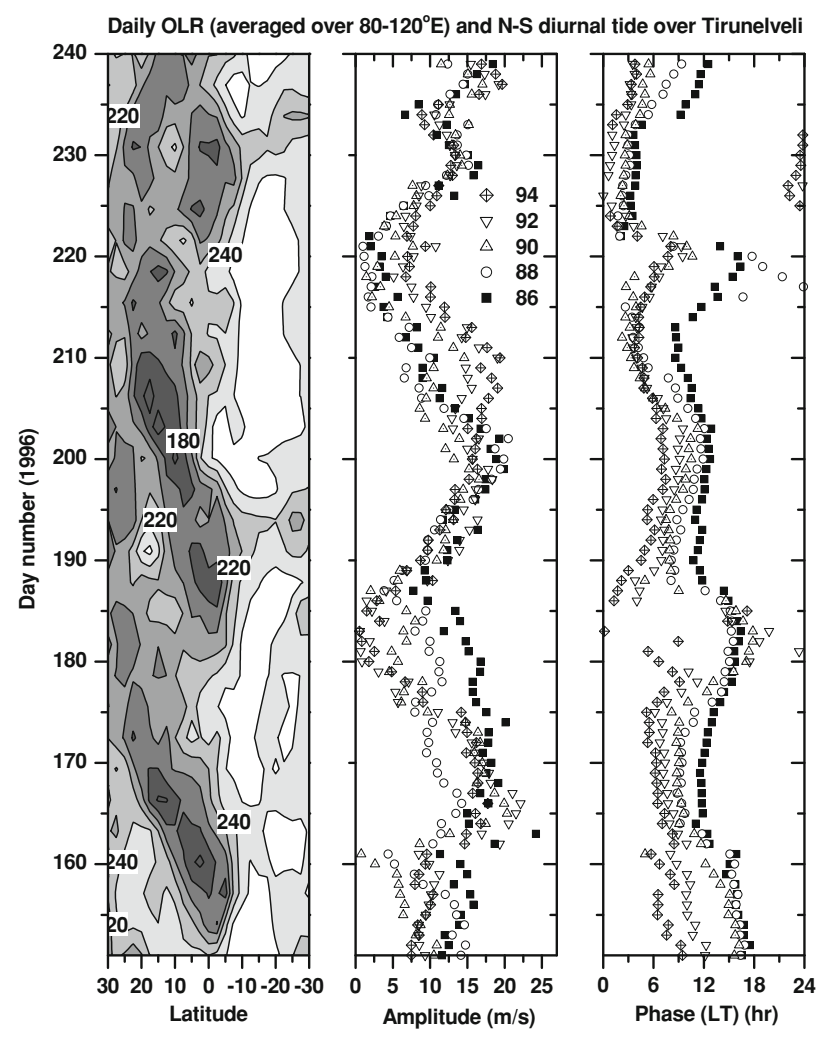

Fig. 10. Daily OLR expressed in $\mathrm{W} \mathrm{m}^{-2}$ (averaged over $80-120^{\circ} \mathrm{E}$ ) and diurnal tide in meridional wind over Tirunelveli (estimates derived from 10-day composite hourly means) for the period June-August 1996.

Figs. 10, 13 and 14. In all these plots, the daily OLR contours averaged for the selected longitude sector corresponding to the latitude region $30^{\circ} \mathrm{N}-30^{\circ} \mathrm{S}$ are depicted in the left panels and the diurnal tide amplitudes and phases are 

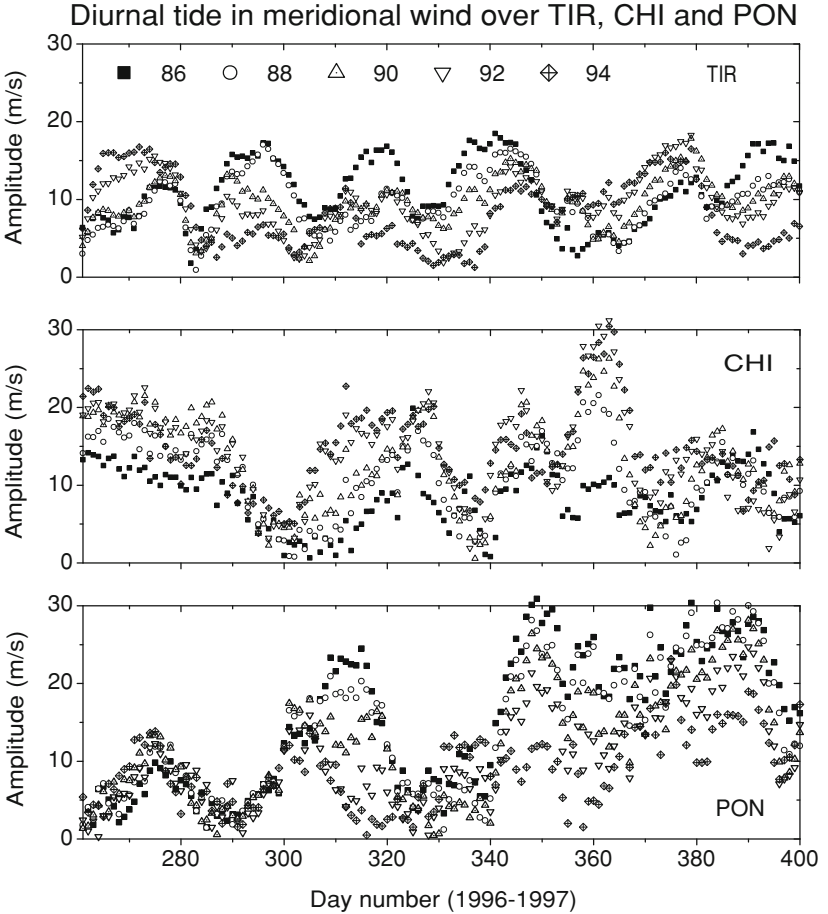

Fig. 11. Same as Fig. 8 but for the period September 1996-January 1997.

Diurnal tide in meridional wind over TIR, $\mathrm{CHI}$ and PON
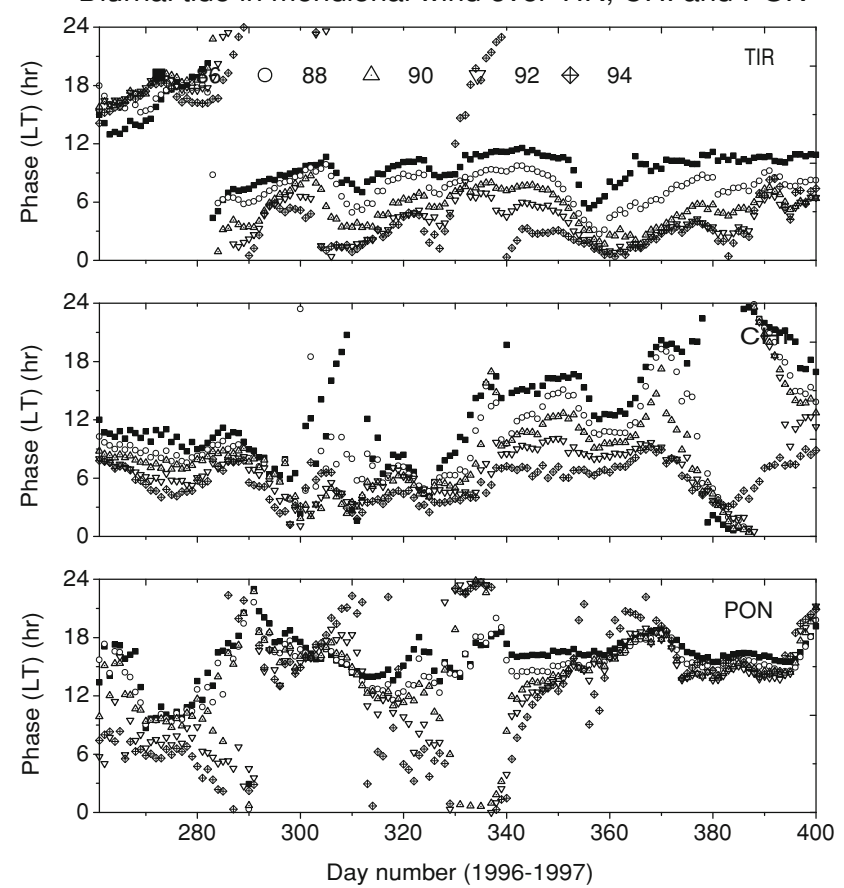

Fig. 12. Same as Fig. 8 but for the phase of the diurnal tide during the period September 1996-January 1997.

plotted in the middle and right panels. Further, the axes are reversed in order to enable easy visual examination of the temporal variations. The dark gray-filled contours on the left panels represent low OLR values in the range 140$180 \mathrm{~W} \mathrm{~m}^{-2}$.

Three convectively active (low OLR) regions occurring one after another at 40-day time intervals in the $80-120^{\circ} \mathrm{E}$ longitude region can be identified in Fig. 10. These con-
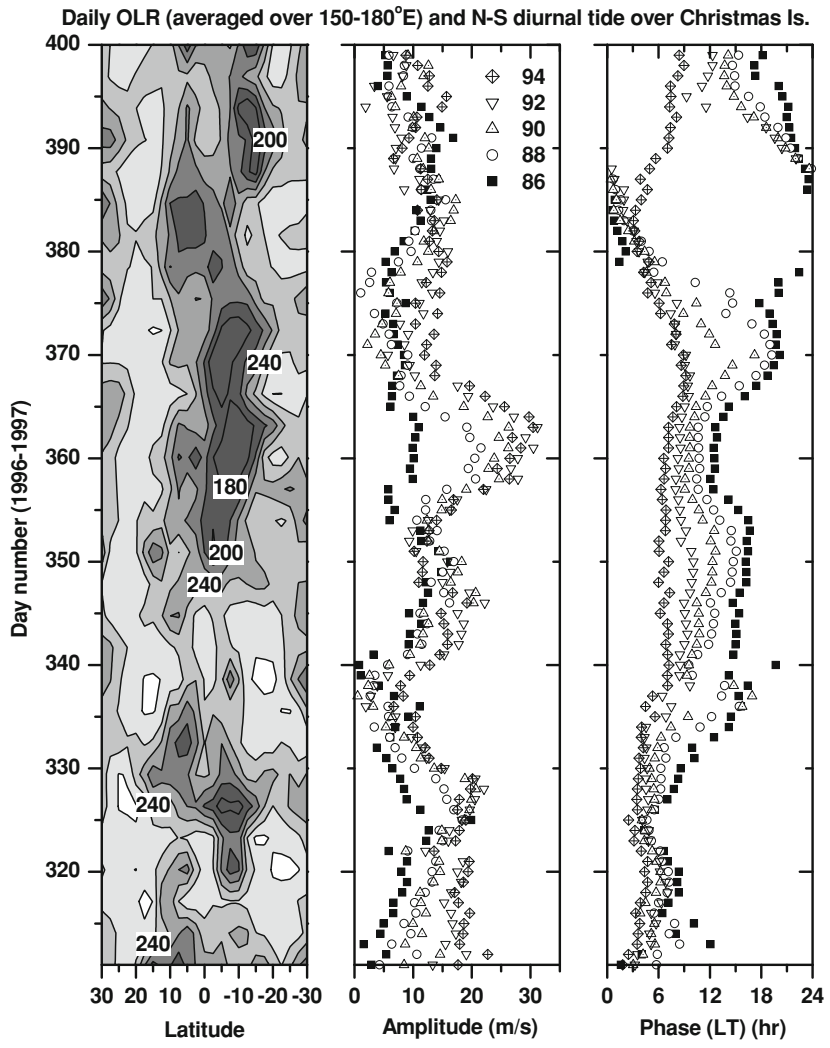

Fig. 13. Daily OLR expressed in $\mathrm{W} \mathrm{m}^{-2}$ (averaged over $150-180^{\circ} \mathrm{E}$ ) and diurnal tide in meridional wind over Christmas Island for the period November 1996-January 1997.

vective clusters seem to originate at the equator and then migrate northwards at a rate of $1.5^{\circ}$ per day. The two broad peaks in tidal amplitudes determined for Tirunelveli appear to be related to the presence of these convective cloud distributions. The phases for the height region 86-94 km during the active periods were in the range 6-12 hrs and indicate upward energy propagation. An interesting observation noticeable in Fig. 10 is that those two peak tidal amplitudes around day numbers 165 and 200 were achieved only when the convective cloud clusters reached $10^{\circ} \mathrm{N}$ latitude. The amplitude variation with the peak observed around day number 230 is not correlated with the migration of convective clouds and subsequent appearance at $10^{\circ} \mathrm{N}$ latitude and has a different characteristic as can be seen with the sharp discontinuity in the phase around day number 220 .

In Figs. 11 and 12 we show the 3-station results for the tidal amplitudes derived for 10-day segments for the period September 1996-January 1997. Though the largest tidal amplitudes were in the range $15-20 \mathrm{~m} / \mathrm{s}$, a 20-30 day modulation can be noticed for Tirunelveli. Over Pontianak, enhanced tidal activity was observed during most of January. Christmas Island amplitudes show a burst in activity towards the end of December. Unlike during the northern summer months of 1996 shown in Fig. 8, there were significant longitudinal differences in the tidal amplitudes during this period that could be ascribed to the presence of nonmigrating tides.

The times of northward wind maximum plotted in Fig. 12 demonstrate the contrasting behavior of the diurnal tide in 
Daily OLR (averaged over $100-140^{\circ} \mathrm{E}$ ) and N-S diurnal tide over Pontianak

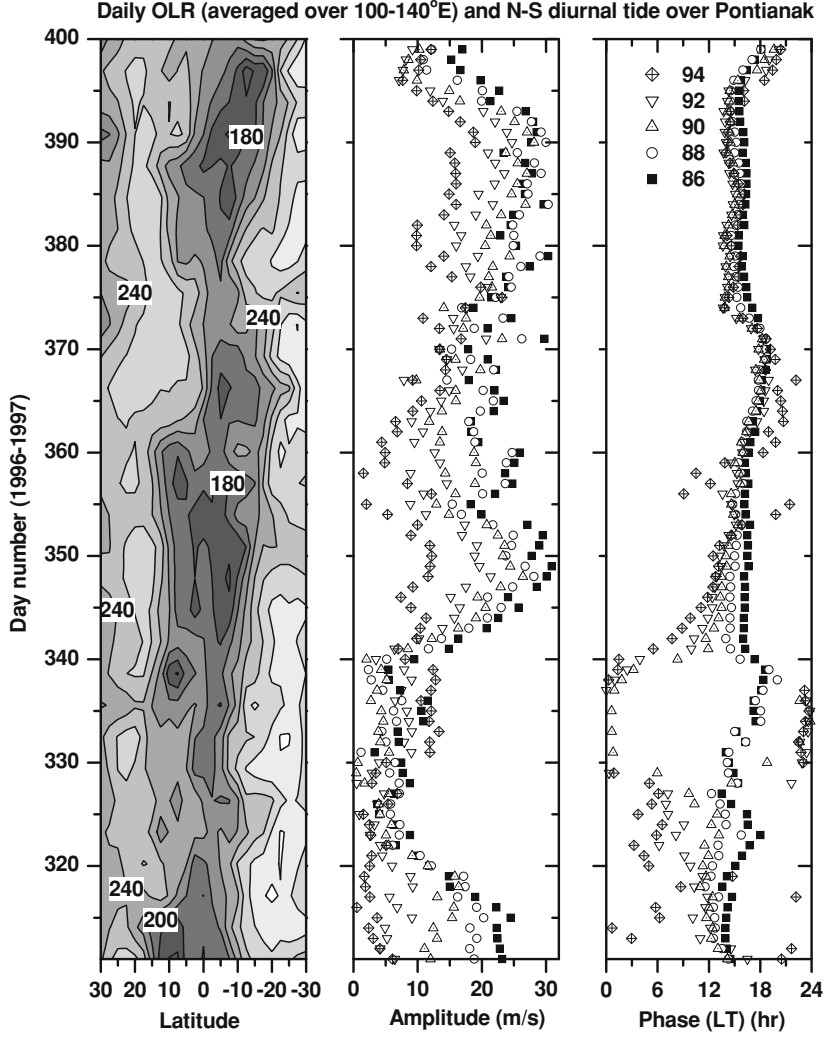

Fig. 14. Daily OLR expressed in $\mathrm{W} \mathrm{m}^{-2}$ (averaged over $100-140^{\circ} \mathrm{E}$ ) and diurnal tide in meridional wind over Pontianak for the period November 1996-January 1997.

the three longitude regions during the southern summer months. Accompanied by moderate tidal amplitudes, the phases over Tirunelveli were nearly constant during much of this period except for a 12-hr shift around day number 280. Both Christmas Island and Pontianak reveal complex phase variations.

Figure 13 depicts the daily OLR variations and the tidal amplitudes and phases for Christmas Island similar to that shown for Tirunelveli in Fig. 10. For comparison with Christmas Island results, the daily OLR values were averaged over the longitude region $150-180^{\circ} \mathrm{E}$ anticipating that the tidal response to deep tropical convection would arise in that region. An intense convectively active region is indeed noticed in Fig. 11 centered a few degrees south of the equator between day numbers 350 and 370. An enhancement in tidal amplitudes (20-30 m/s) occurred at all heights except $86 \mathrm{~km}$ around this time. The phase of the diurnal tide varied considerably during this 90-day period, though at times of enhanced activity around day number 360 the phases were in the range 6-12 hrs.

Figure 14 depicts the comparison for Pontianak diurnal tide observations. The daily OLR in this case was averaged over $100-140^{\circ}$ E. Low OLR values $\left(<200 \mathrm{~W} \mathrm{~m}^{-2}\right)$ around day number 350 imply high cloud tops that could be ascribed to deep tropical convection centered a few degrees south of the equator. Though the tidal amplitudes showed an enhancement around day number 350 , the phases show little variation with height. The diurnal tide decayed above $86 \mathrm{~km}$ during much of this period as can be seen in the am- plitude plot. The tidal response over Pontianak seems to be distinctly different from the ones shown for Tirunelveli and Christmas Island. The short-term observations presented in this section serve well to demonstrate the richness in the tidal variabilities both temporally and longitudinally that is yet to be addressed in any numerical modeling efforts.

\section{Discussion and Conclusions}

The work presented here has made use of simultaneous MLT radar observations from three low latitude regions with the objective of delineating both long- and short-term diurnal tide variabilities and addressing the longitudinal differences in the observed tidal characteristics.

The first part of this work focused on the long-term observations of diurnal tide at the mesopause height of $86 \mathrm{~km}$ over Kauai and Tirunelveli. The monthly determinations of diurnal tide amplitude shown over a 10-year period (1993-2002) reveal a remarkable QBO signature in both the zonal and meridional components of the diurnal tide over Tirunelveli. Comparison with the stratospheric QBO wind at $10 \mathrm{hPa}$ shows that the amplitudes were larger (smaller) during the eastward (westward) phase of the QBO. The QBO westward phase had a longer duration of $\sim 18$ months between 1999 and 2001, which was longer than earlier phases. It is noteworthy that the northward component of the diurnal tide was characterized by small monthly amplitudes $(<10 \mathrm{~m} / \mathrm{s})$ during this extended westward QBO phase. A similar, strong QBO signal could not be traced in the long-term observations from Kauai.

While performing a comparative study on seven-year (1993-1999) simultaneous observations from Jakarta and Tirunelveli, Gurubaran et al. (2005) interpreted the observed interannual variability of the diurnal tide in terms of a possible role played by the deep tropical convection in the western Pacific region. When examined on month-tomonth basis, the meridional component of the diurnal tide over Jakarta exhibited a pronounced annual cycle that was modulated on interannual time scales. Noting a similarity in the seasonal progression of the deep tropical convection and its interannual variation caused by the El Nino Southern Oscillation (ENSO) and the observed seasonal and interannual variabilities of diurnal tide in the mesosphere over Jakarta, Gurubaran et al. (2005) suggested the deep tropical convection as a possible source of tidal variability in the mesosphere.

Two observational features may be noted in the context of the earlier report by Gurubaran et al. (2005) and has relevance to the observations made in the present work. The El Nino of 1998 occurred when the stratospheric QBO was in the westward phase and low tidal amplitudes were indeed observed over both Jakarta and Tirunelveli. With QBO link demonstrated in the present work, it is not quite clear whether the reduced diurnal tide activity over the maritime continent during 1998 was due to (i) the absence of convective clouds over the western Pacific because of their eastward migration during the El Nino or (ii) the westward phase of the QBO generating unfavorable conditions for the tidal activity to show up in the mesosphere. Smaller tidal amplitudes were also observed during 1996 when a warm oceanic pool surrounded the maritime continent as revealed 
by the presence of convective clouds in the OLR maps and controlled the normal seasonal progression of the deep tropical convection in the western Pacific. In the light of the inferences made in this work, the suppressed tidal activity during 1996 could very well be due to the QBO wind system in the stratosphere which was in the westward phase then.

The seasonal variabilities in the diurnal tide reported for the three low latitude sites, Christmas Island, Jakarta and Tirunelveli, during the years 1993-1997, do have longitudinal differences as can be noted in Figs. 3 and 4. Whereas Christmas Island (and Kauai) and Tirunelveli have, in general, a common seasonal variability with equinoctial maxima and solstitial minima, the meridional component over Jakarta has a strong annual variability with maximum amplitudes occurring during local summer months. The zonal component over Tirunelveli shows another maximum during June months and the zonal component over Jakarta has smaller amplitudes during December and January months.

With simultaneous observations from three low latitude sites, we also had an opportunity to study the longitudinal differences in the seasonal patterns of the times of occurrences of maximum eastward and northward diurnal tidal winds. The observed phases, especially during solstices, deviate considerably from the GSWM02 model results that have included migrating and nonmigrating tidal solutions.

The last part of the work presented herein examines the short-term (several days to a few tens of days) tidal variabilities over the three low latitude sites, Christmas Island, Pontianak and Tirunelveli, with an attempt to relate some of them to the short-term variations in the deep tropical convective activity. During the northern summer monsoon period (June-August) of 1996, a remarkable 30-40 day modulation of diurnal tide activity was observed over all the three sites, though the times of occurrence of maximum and minimum amplitudes differed slightly among the sites. The daily OLR over the $80-120^{\circ} \mathrm{E}$ longitude region showed variations in similar time scales. In particular, a convectively active region appeared first in the Indian Ocean close to the equator during the first week of June and then migrated northwards. Another convective cluster that appeared about 30 days later exhibited similar northward migration. The observed diurnal tide variations over the low latitude sites appear to be linked to the source variations during this period. The phases over Tirunelveli and Pontianak showed similar temporal variations but differed by 3-6 hours with Pontianak leading Tirunelveli.

A similar correlative analysis performed for the September 1996-January 1997 period revealed considerable variability at Pontianak during the convectively active months of December and January. Deep tropical convection occurred during the last week of December in the western to central Pacific as can be seen in the left panels of Figs. 13 and 14. Whereas over Pontianak the diurnal tide amplitudes decayed rapidly above $86 \mathrm{~km}$ leading to little phase variation with height, the tidal activity over Christmas Island reveals amplitudes growing with height with downward phase propagation. Because we have used composite hourly values from 10-day means, any transient variations due to background winds contributing to diurnal harmonic can be safely ignored. It is suggested that nonmigrating tides generated due to latent heat release in the deep convective clouds (Hagan and Forbes, 2002) become important at mesospheric heights and interfere with the dominant migrating tide leading to an overall reduction in tidal amplitudes at higher altitudes over Pontianak. This process could also contribute to the significant longitudinal variability in the tidal amplitudes and phases noticed in the observational data sets. A possible role of nonmigrating tides contributing to significant longitudinal variability of the diurnal tide at MLT heights was suggested in several reports in the past (e.g., Forbes et al., 2003).

Acknowledgments. The daily OLR data were provided by the NOAA-NCEP Climate Prediction Center and are readily available on their web site. Efforts of Maura Hagan in making available the GSWM02 results to the scientific community are acknowledged. Part of the work presented here was carried out by the first author at the Research Institute for Sustainable Humanosphere, Kyoto University, and this effort contributed to the Coupling Processes in the Equatorial Atmosphere (CPEA) program.

\section{References}

Akmaev, R. A., Simulation of large-scale dynamics in the mesosphere and lower thermosphere with the Doppler-spread parameterization of gravity waves, 2. Eddy mixing and the diurnal tide, J. Geophys. Res., 106, 1205-1213, 2001.

Andrews, D. G., J. R. Holton, and C. B. Leovy, Middle Atmosphere Dynamics, 489 pp., Academic, San Diego, Calif., 1987.

Baldwin, M. P., L. J. Gray, T. J. Dunkerton, K. Hamilton, P. H. Haynes, W. J. Randel, J. R. Holton, M. J. Alexander, I. Hirota, T. Horinouchi, D. B. A. Jones, J. S. Kinnersley, C. Marquadt, K. Sato, and M. Takahashi, Rev. Geophys., 39, 179-229, 2001.

Burrage, M. D., M. E. Hagan, W. R. Skinner, D. L. Wu, and P. B. Hays, Long-term variability in the solar diurnal tide observed by HRDI and simulated by the GSWM, Geophys. Res. Lett., 22, 2641-2644, 1995.

Chang, J. L. and S. Avery, Observations of the diurnal tide in the mesosphere and lower thermosphere over Christmas Island, J. Geophys. Res., 102, 1895-1907, 1997.

Chapman, S. and R. S. Lindzen, Atmospheric Tides, D. Reidel, Dordrecht, Holland, 1970.

Forbes, J. M., Middle atmosphere tides, J. Atmos. Terr. Phys., 46, 10491067, 1984.

Forbes, J. M., X. Zhang, E. R. Talaat, and W. Ward, Nonmigrating diurnal tides in the thermosphere, J. Geophys. Res., 108(A1), 1033, doi:10.1029/2002JA009262, 2003.

Geller, M. A., V. A. Yudin, B. V. Khattatov, and M. E. Hagan, Modeling the diurnal tide with dissipation derived from UARS/HRDI measurements, Ann. Geophys., 15, 1198-1204, 1997.

Gurubaran, S. and R. Rajaram, Long-term variability in the mesospheric tidal winds observed by MF radar over Tirunelveli $\left(8.7^{\circ} \mathrm{N}, 77.8^{\circ} \mathrm{E}\right)$, Geophys. Res. Lett., 26, 1113-1116, 1999.

Gurubaran, S., R. Rajaram, T. Nakamura, and T. Tsuda, Interannual variability of diurnal tide in the tropical mesopause region: A signature of the El Nino-Southern Oscillation (ENSO), Geophys. Res. Lett., 32, L13805, doi:10.1029/2005GL022928, 2005.

Hagan, M. E. and J. M. Forbes, Migrating and nonmigrating diurnal tides in the middle and upper atmosphere excited by tropospheric latent heat release, J. Geophys. Res., 107(D24), 4754, doi:10.1029/2001JD001236, 2002.

Hagan, M. E. and R. G. Roble, Modeling diurnal tidal variability with the National Center for Atmospheric Research thermosphere-ionospheremesosphere-electrodynamics general circulation model, J. Geophys. Res., 106, 24,869-24,882, 2001.

Hagan, M. E., M. D. Burrage, J. M. Forbes, J. Hackney, W. J. Randel, and X. Zhang, QBO effects on the diurnal tide in the upper atmosphere, Earth Planets Space, 51, 571-578, 1999.

Hagan, M. E., J. M. Forbes, and F. Vial, On modeling migrating solar tides, Geophys. Res. Lett., 22, 893-896, 1995.

Khattatov, B., V. Yubin, M. Geller, P. Hays, and R. Vincent, Diurnal migrating tide as seen by the high-resolution Doppler imager/UARS 1 . 
Monthly mean global meridional winds, J. Geophys. Res., 102, 44054422, 1997.

Lieberman, R. S., D. A. Ortland, and E. S. Yarosh, Climatology and interannual variability of diurnal water vapor heating, J. Geophys. Res., 108(D3), 4123, doi:10.1029/2002JD002308, 2003.

Lieberman, R. S., J. Oberheide, M. E. Hagan, E. E. Remsberg, and L. L. Gordley, Variability of diurnal tides and planetary waves during November 1978-May 1979, J. Atmos. Sol.-Terr. Phys., 66, 517-528, 2004.

Lieberman, R. S., D. M. Riggin, D. A. Orland, S. W. Nesbitt, and R. A. Vincent, Variability of mesospheric diurnal tides and tropospheric diurnal heating during 1997-1998, J. Geophys. Res., 112, D20110, doi:10.1029/2007/JD008578, 2007.

Mayr, H. G. and J. G. Mengel, Interannual variations of the diurnal tide in the mesosphere generated by the quasi-biennial oscillation, J. Geophys. Res., 110, D10111, doi:10.1029/2004JD005055, 2005.

Mayr, H. G., J. G. Mengel, K. L. Chan, and H. S. Porter, Seasonal variations of the diurnal tide induced by gravity wave filtering, Geophys. Res. Lett., 25, 943-946, 1998.

Mayr, H. G., J. G. Mengel, K. L. Chan, and H. S. Porter, Mesosphere dynamics with gravity wave forcing: Part I, Diurnal and semidiurnal tides, J. Atmos. Sol.-Terr. Phys., 63, 1851-1864, 2001.

Mayr, H. G., J. G. Mengel, E. R. Talaat, H. S. Porter, and K. L. Chan, Nonmigrating diurnal tides generated with planetary waves in the mesosphere, Geophys. Res. Lett., 30(16), 1832, doi:10.1029/2003GL017877, 2003.

McLandress, C., The seasonal variation of the propagating diurnal tide in the mesosphere and lower thermosphere, Part I: The role of gravity waves and planetary waves, J. Atmos. Sci., 59, 893-906, 2002a.

McLandress, C., Seasonal variation of the propagating diurnal tide in the mesosphere and lower thermosphere, Part II: The role of tidal heating and zonal mean winds, J. Atmos. Sci., 59, 907-922, 2002b.

McLandress, C., Interannual variations of the diurnal tide in the rmesosphere induced by a zonal-mean wind oscillation in the tropics, Geophys. Res. Lett., 29, 1035, doi:10.1029/2001GL014551, 2002c.

Meyer, C. K., Gravity wave interactions with the diurnal propagating tide, J. Geophys. Res., 104, 4223-4239, 1999.

Miyoshi, Y., Temporal variation of nonmigrating diurnal tide and its relation with the moist convective activity, Geophys. Res. Lett., 33, L11815, doi:10.1029/2006GL026072, 2006.

Nakamura, T., D. C. Fritts, J. R. Isler, T. Tsuda, R. A. Vincent, and I. M. Reid, Short-period fluctuations of the diurnal tide observed with low- latitude MF and meteor radars during CADRE: Evidence for gravity wave/tidal interactions, J. Geophys. Res., 102, 26,225-26,238, 1997.

Oberheide, J. and O. A. Gusev, Observations of migrating and nonmigrating diurnal tides in the equatorial lower thermosphere, Geophys. Res. Lett., 29(24), 2167, doi:10.1029/2002GL016213, 2002.

Oberheide, J., Q. Wu, T. L. Killeen, M. E. Hagan, and R. G. Roble, Diurnal nonmigrating tides from TIMED Doppler Interferometer wind data: Monthly climatologies and seasonal variations, J. Geophys. Res., 111, A10S03, doi:10.1029/2005JA011491, 2006.

Talaat, E. R. and R. S. Lieberman, Nonmigrating diurnal tides in mesospheric and lower thermospheric winds and temperatures, J. Atmos. Sci., 56, 4073-4087, 1999.

Teitelbaum, H. and F. Vial, On tidal variability induced by nonlinear interaction with planetary waves, J. Geophys. Res., 96, 14,169-14,178, 1991.

Tsuda, T., S. Fukao, M. Yamamoto, T. Nakamura, M. D. Yamanaka, T. Adachi, H. Hashiguchi, N. Fujioka, M. Tsutsumi, S. Kato, S. W. B. Harijono, T. Sribimawati, B. P. Sitorus, R. B. Yahya, M. Karmini, F. Reneggono, B. L. Parapat, W. Djojonegoro, P. Mardio, N. Adikusumah, H. T. Endi, and H. Wiryosumarto, A preliminary report on observations of equatorial atmosphere dynamics in Indonesia with radars and radiosondes, J. Meteor. Soc. Jpn., 73, 393-406, 1995.

Tsuda, T., K. Ohnishi, F. Isoda, T. Nakamura, R. A. Vincent, I. M. Reid, S. W. B. Harijono, T. Sribimawati, A. Nuryato, and H. Wiryosumarto, Coordinated radar observations of atmospheric diurnal tides in equatorial region, Earth Planets Space, 51, 579-592, 1999.

Vincent, R. A. and D. Lesicar, Dynamics of the equatorial atmosphere: First results with a new generation partial reflection radar, Geophys. Res. Lett., 18, 825-828, 1991.

Vincent, R. A., S. Kovalam, D. C. Fritts, and J. R. Isler, Long-term MF radar observations of solar tides in the low latitude mesosphere: Interannual variability and comparisons with GSWM, J. Geophys. Res., 103, 8667-8683, 1998.

Walterscheid, R. L., Inertia-gravity wave induced accelerations of mean flow having an imposed periodic component: Implications for tidal observations in the meteor region, J. Geophys. Res., 86, 9698-9706, 1981.

S. Gurubaran (e-mail: gurubara@iigs.iigm.res.in), R. Rajaram, T. Nakamura, T. Tsuda, D. Riggin, and R. A. Vincent 